\title{
CORRESPONDENCE
}

\section{OCULAR DISEASE DUE TO BRUCELLOSIS}

\section{To the Editorial Committee of the British Journal OF Ophthalmology}

DEAR SIRS-I read with great interest the article by Dr. K. D. Foggitt in your issue of May, 1954, entitled " Ocular Disease Due to Brucellosis ", and I welcome this reminder of the ocular complications of brucella infection.

A good deal of attention has been paid to this subject by Molinelli and his coworkers in Uruguay and also by Cremona in Argentina. Thus Molinelli and others (1947) found ocular signs in 41 cases out of a total of 95 patients examined; in about half these cases the fundus alone was affected. Cremona (1951) examined 160 patients for eye lesions and found them in 89 cases (55 per cent.), in 76 of which there was venous congestion of the fundus oculi, and in 33 allergic conjunctivitis. These cases were all found in the eastern part of Argentina and were therefore due to infection with $\mathrm{Br}$. suis or $\mathrm{Br}$. abortus.

At the Johns Hopkins Hospital, Bryer, Schoenbach, Wood, and Long (1949) found a central retinal haemorrhage, not recent, in the region of the right fovea in a case about 93 days after onset. Romer (1949) reported a case in which ophthalmoscopic examination revealed a recent thrombosis of the central retinal vein.

Grant and Stote (1953) reported a case in which death was due to rupture of the heart resulting from a $\mathrm{Br}$. abortus endocarditis; the patient had complained of a sudden partial loss of vision in the right eye, which on examination proved to be due to pale patches below and to the nasal side of the disc with a complete central scotoma. Leys (1943) published eight Scottish cases of undulant fever, in one of which there was an ocular palsy.

As regards my own experience, in a series of 1,134 cases, complete blindness of one eye due to a retinal haemorrhage occurred in one and partial blindness in another; though these were the only serious eye conditions, transient visual disturbances (nystagmus, diplopia, difficulty in focusing, etc.) occurred in 68 cases, whilst there was conjunctivitis in three cases, eye-ache in seven cases, etc.

As regards Dr. Foggitt's general account of the disease, this is no place to discuss this in detail, but I should like to make one or two observations. I think that his statement that "Brucellosis frequently occurs without serological evidence" is a considerable exaggeration, though this is impossible to prove.

Of my first 983 cases (Dalrymple-Champneys, 1950a, b), the agglutination was negative in only one, though the infection was proved by blood culture. The result depends, of course, on what criteria of infection are accepted, and those adopted by some workers are, I feel, extremely shaky.

With reference to Dr. Foggitt's estimation of the value of the intradermal brucellin test, I think he rates the value of this test far to high. Without going into 
the evidence, I would call his attention to the Second Report of the Joint FAO/ WHO Expert Committee on Brucellosis (1953), over which I had the honour to preside, in which it is stated:

A positive intradermal test denotes a specific allergic condition of the individual and should be regarded as free from other diagnostic significance r r gardless of the antigen or technique employed; it certainly does prove the presence of an active infection. The chief value of the test is for epidemiological purposes.

A much more serious statement in Foggitt's paper is that:

A healthy portion of liver obtained at biopsy will rule out with sufficient certainty the possibility of brucellosis.

The truth of this statement could only be disproved by carrying out such biopsies on a large series of cases, but, though I would agree that the liver is often affected at least temporarily, it seems very doubtful whether such localization is at all constant. In the large series I have already quoted, enlargement of the liver was detected in only 62 cases. Therefore, in view of the definite though perhaps small risks of a liver biopsy, I feel that this method should be used with considerable caution and not resorted to whenever the diagnosis is in doubt following negative results in the more usual tests.

Ministry of Health, Savile Row, Yours faithfully,

W. Dalrymple-Champneys.

$$
\text { LONDON, W.1 }
$$

June 22, 1954.

\section{REFERENCES}

Bryer, M. S., Schoenbach, E. B., Wood, R. M., and Long, P. H. (1949). Bull. Johns. Hopkins Hosp:; 84, 444.

Cremona, A. C. (1951). Rev. Ass. med. Argent., 65, p. 163.

DalRYMPLe-ChampNeYs, W. (1950a). Lancet, 1, 429. (1950b). Ibid., 1, 477.

FoGGITT, K. D. (1954). British Journal of Ophthalmology, 38, 273.

Grant, G. H., and Stote, C. L. (1953). Brit. med. J., 1, 951.

LEYS, D. G. (1943). Ibid., 1, 187.

Molinelli, E. A., Ithurrat, E. M. F., Basso, G. (1947). " Memoria del Primer Congreso Nacional de la Brucelosis ", p. 439. Montevideo.

ROMER, C. (1949). Brit. med.J., 1, 1035.

World Health Organization (1953). Tech. Rep. Ser., No. 67.

\section{NOTES}

\section{Faculty of Ophthalmologists Study Tours, 1954}

\section{SCANDINAVIA}

Copenhagen.-The party was cordially received on May 24 by Professor Ehlers and his wife, and his Danish colleagues. Professor Ehlers showed us round the out-patients' department and laboratories of the Rigs hospital. This hospital receives cases for scientific research and post-graduate training, other cases being treated at the municipal hospitals; it also contains the only orthoptic clinic seen on the tour. At Tscherning's 